\title{
New initiatives in Australia for education and training in the academic and industrial optical communications communities
}

John Love

John D. Love, "New initiatives in Australia for education and training in the academic and industrial optical communications communities," Proc. SPIE 4588, Seventh International Conference on Education and Training in Optics and Photonics, (28 May 2002); doi: 10.1117/12.468729

SPIE Event: Education and Training in Optics and Photonics 2001, 2001, Singapore, Singapore 


\title{
New Initiatives in Australia for Education and Training in the Academic and Industrial Optical Communications Communities
}

\author{
John D. Love \\ Photonics Institute Pty Ltd \\ Australian Photonics Cooperative Research Centre \\ Research School of Physical Sciences \& Engineering, Australian National University, Canberra, ACT \\ 0200, Australia; e-mail jd1124@rsphysse.anu.edu.au; phone 6126125 4691; fax 61261258588
}

\begin{abstract}
Photonics education and training in Australia, like many other countries with a strong photonics industry base, is going through a stage of rapid evolution to meet the anticipated requirements of industry and other sectors over the next decade. Additional support and promotion of these and other activities at various levels of education and training from school through to university and industry is being introduced through the recently established Photonics Institute, which is planned to become a national focus in photonics. This talk will summarise the various activities of the Photonics Institute that are helping to achieve this goal.
\end{abstract}

Keywords: Education, training, outreach, photonics

\section{INTRODUCTION}

\subsection{Background}

Research into optical communications in Australia dates back to the 1960's and in particular to the decision of Professor Tony Karbowiak in 1965 to move from the Harlow research laboratories of Standard Telephones Ltd to a Chair at the University of New South Wales in Sydney. At Harlow, Professor Karbowiak had been working with and strongly encouraging one of the now acknowledged founders of modern optical telecommunications - Dr Charles Kao [1] - and continued this encouragement with his new Australian colleagues in Sydney.

As a result of this momentum and an increasing interest in optical communications from other areas of the Australian telecommunications equipment and service suppliers and from other academic groups, there has been an ever-expanding research activity since. Indeed, in 1972, a liquid core fibre developed jointly between Australian government and industry achieved a then world record low for fibre transmission loss of $7 \mathrm{~dB} / \mathrm{km}$ [2]. In 1976, the first annual meeting of the now national Australian Conference on Optical Fibre Technology (ACOFT) was held, and preceded the inaugural European Conference on Optical Communications in London (ECOC) by several months!

Today, there is a flourishing optical communications industry in Australia with combined exports of well over $\$ 1$ billion. The majority of this activity originates from a small number of indigenous start-up companies that emerged in the early 1970's and 1980's, together with a plethora of spin-offs that have appeared in the last few years and established multinational companies from overseas that have moved into optical communications. Optical communications research is spread across some dozen Universities, and the majority of this activity is now associated with the Australian Photonics Cooperative Research Centre (CRC). This Centre is funded by both government and industry and is charged with progressing optical communications from blue-sky research through to commercialisation.

Optical communications has been an evolving area of research since it was demonstrated in the mid-1960's that long-

distance propagation of light pulses in optical fibres was a practical reality. The photonics industry has had a commensurate development path over the last 25 years to match the rapidly expanding deployment of optical communications systems 
across the world both on land and in the oceans. This juxtaposition provided sufficient capacity to meet the increasing needs of voice-based telephony. However, with the advent of the Internet, the demand for capacity has escalated dramatically, and has resulted in the establishment of a plethora of new companies world wide who are striving to meet this demand.

The demand for photonics-educated and trained personnel is matching this pace and is resulting in an insatiable thirst for suitably educated workers for industry at the technical, tertiary and postdoctoral levels. A recent survey in Australia sponsored by the CRC identified the need for 25,000 new workers at all levels over the next 10 years from a population base of less than 20 million people [3]. To meet this demand, new courses and degrees are appearing at a number of technical and tertiary institutions. The CRC is providing support for these initiatives through a program of strategic new initiatives, including a national Photonics Institute, a national Outreach Program for schools, the development of photonics modules for both lecture theatre and distance learning, and the provision of tailored in-house industry courses [4]. The talk will elaborate on the structure, strategies and linkages involved in this program.

\section{PHOTONICS EDUCATION \& TRAINING IN AUSTRALIA}

\subsection{High School Photonics}

Photonics has already been taught for several years in a number of Schools at the initiative of individual science teachers. Now various Australian State and Territory Education Departments are beginning to incorporate formally photonics into their curricula, mainly in the final pre-university year-12, based on a simple understanding of light transmission along a fibre together with a practical demonstration of this and other simple fibre phenomena such as light attenuation. However, whilst the curricula development may be straightforward, there is a challenge to supply appropriate photonics technical information and simple experimental fibre optic kits to both students and teachers.

The Photonics Institute is taking steps to address both issues. On the technical side, there is a plethora of photonics scientists involved in the CRC who can contribute to both theory and experiment. This will also involve the development of a classroom-safe fibre optic kit, probably incorporating plastic fibre and bright white light sources rather than glass fibres, with associated "stick" injury problems and lasers with eye safety issues. There will also be a need for science teacher workshops, especially as not all science teachers have a physics background, to help with the transfer of photonics to the classroom.

\subsection{Technical Education}

Australia already has several commercial fibre-optic transmission networks spanning the country that between them link all cities and most towns. As a by-product Australia has the highest length of installed fibre per head of population, around 1 $\mathrm{km}$, of any country in the world. These networks include railway-based systems as well as telecommunications company systems. In addition, there are an increasing number of submarine fibre systems radiating from Australia across the Pacific and Indian Oceans and into South East Asia. The maintenance of this infrastructure, together with the requirements of a growing number of companies involved in the production of fibres, fibre devices, planar waveguides, platforms, systems and sub-systems is requiring an increasing number of technically qualified personnel with at least basic training in electronics and photonics.

Vocational training in Australia is provided mainly by the Technical and Further Education (TAFE) system of colleges in most States and Territories, who have developed or are developing photonics modules to integrate with electronics-based modules as the basis for e.g. an Advanced Diploma in Photonics Technology. Some of these modules evolve to meet the specific requirement of individual photonics-based companies, while others have a more generic content. The Photonics Institute is helping with the development of the curricula for the latter and the professional development of TAFE lecturers.

\subsection{Undergraduate Education}

Photonics has been part of later year undergraduate courses, diploma and other graduate courses at a number of Australian universities for many years, and particularly in Electrical Engineering Departments. The 1990's saw the establishment of the first Optoelectronics Degree at Macquarie University. In 2002 full degrees in photonics/optoelectronics commence at 
four other universities in New South Wales, South Australia, Victoria and the Australian Capital Territory and more are planned. Part of the rationale for these new degrees is strongly motivated by the anticipated numbers of graduates required by the Australian photonics industry over the coming decade, while the future prospects of some university physics departments that have been in decline in recent years has been another factor.

\subsubsection{Photonics Modules}

To help faciliate with the delivery of these new degrees and courses, a range of theory and laboratory-based photonics modules is being developed by the Photonics Institute with funding from a Commonwealth Government Science Lectureship Initiative grant. Several CRC-linked universities are involved in supplying material for their development. Modules for delivery by lecture at the 3-4 year undergraduate level and later for distance learning are at varying stages of development. A total set of around 15-20 modules is planned and will be made available to any educational institution nationally or internationally through the Photonics Institute.

\subsection{Postgraduate Education}

The key focus of the CRC's Education and Training has been in supporting postgraduate research, predominantly towards the $\mathrm{PhD}$ in the member universities. The $\mathrm{CRC}$ has been able to enhance the quality of research degrees through student access to a wider range of research equipment funded by the CRC, collaborative projects between universities and joint supervision between CRC universities and member companies, fully-funded and top-up scholarships from the CRC and its Redfern Photonics group of spin-off companies, and enhanced conference and travel support.

\subsubsection{Photonics School}

A special feature of postgraduate training has been the Photonics School promoted by the Photonics Institute to help broaden student knowledge across a broader area of photonics and also including aspects of IP, patents and contracts. The 3day event comprises a series of lectures by leading photonics experts from within the CRC and elsewhere, together with exposure to hands-on photonics experiments.

\subsection{Advanced Industry Short Courses}

To meet some of the advanced training requirements of the expanding Australian photonics industry, special in-house courses have been developed and delivered to suit the particular photonics interests of a number of companies. These courses range from basic introductory courses on optical communications through to specialised courses directly focused on part of the companies technical interests.

\subsection{Photonics Institute}

The Photonics Institute is an initiative of the CRC that has been established to serve a range of purposes. In the longer term, the Photonics Institute is planned to become the successor to the CRC, when funding from the Commonwealth Government ceases, and will become the focal point for all of the current CRC activities including research. In the shorter term, the Photonics Institute has taken over the Education and Training activities of the $\mathrm{CRC}$, including outreach and industry courses.

The Photonics Institute is strategically located in the nation's capital, Canberra, and its initial financial support is partly funded from the Commonwealth Government and the local Australian Capital Territory Government, as well as from the CRC. Its premises were formally opened on 5 September 2001 and already the Photonics Institute is making its presence felt through both local and national activities.

\subsection{Outreach Activities}

A major activity in Australia that is gaining momentum is the promotion of photonics within the educational and public sectors, particularly at the secondary education level. There is a realtively low awareness of photonics in the general community and a number of strategies have been put in place to help raise the understanding of photonics and compliment other existing activities. 
Two science presenters from the National science and Technology Centre have been engaged by the Photonics Institute and are travelling the length and breadth of Australia delivering a travelling photonics show to school audiences in both the major cities and the outback. There has been a very positive response to these shows by both students and science teachers as follow up surveys have quantified. Other photonics presentations are being undertaken at schools within states and cities by professional groups, such as the Australian Institute of Physics, and by researchers and academics from individual universities. Focussed workshops and material on photonics are also being organised to meet the specific needs of the science teachers' community.

\section{FUTURE DEVELOPMENTS}

For the immediate future, there will be continuation of the various activities of the Photonics Institute as outlined above. A broader initiative to be developed in 2002 will be the establishment of a National Photonics Education and Training Network, covering school, TAFE and university activities across Australia. This concept is planned to have several components, including a web-based data base for degrees, course, curricula, etc, and a video conferencing network for the presentation of lectures, seminars, hands-on demonstrations, etc. Another component will provide an electronic job centre for companies and individuals.

\section{References}

1. K.C. Kao \& G.A. Hockham: "Dielectric-fibre surface waveguides for optical frequencies" Proceedings IEE, 113, pp.1151-1158, (1966).

2. G.J. Olgivie, R.J. Esdaile \& G.P. Kidd: "Transmission loss of tetrachloroethylene-filled liquid-core fibre light guide", Electronics Letters, 8, pp.533-534, (1972).

3. Techkne Pty Ltd, Canberra, 1999

4. Australian Photonics Cooperative Research Centre, Annual Report 2000-2001 